\title{
北米スポーツマネジメント学会 2016 年度大会 \\ The North American Society for Sport Management Conference 2016
}

相澤くるみ（早稲田大学スポーツナレッジ研究所）

31 回目となる2016年北米スポーツマネジメント学会 (North American Society for Sport Management Conference : 以下「NASSM」と略す）が、2016年 6 月 2 日から 6 月 4 日にかけてフロ リダ州オーランドで開催された。本学会には、世界各国から 574 名の研究者、実務家、学生が参加 した。研究発表の応募総数は 463 件、採択数は 349 件（採択率 $75.4 \%$ ）であり、例年よりも採択率 の高い大会であった。

\section{研究分野別の動向}

表 1 に過去 3 年間の研究分野別発表件数の推移をまとめた。2014 年、2015 年同様に、マーケテ イング分野の研究発表が最も多く、全体の $26.3 \%$ を占めている。次いで、社会・文化的側面に関す る分野 (13.9\%)、マネジメント／リーダーシップに関する分野（13.0\%）の発表が多く、上位 3 つ の分野で総発表件数の $50 \%$ 以上を占める。他の分野については、組織論／組織文化、倫理学に関 する研究発表が増加しているが、全体として、2015 年度大会と類似した傾向を示している。

\section{表 1 過去 3 年間の研究分野別発表数の増減}

\begin{tabular}{|c|c|c|c|c|c|}
\hline 分野 & & 2014 & 2015 & & 2016 \\
\hline マーケティング（Marketing） & 81 & $(27.2 \%)$ & $65(26.7 \%)$ & 89 & $(26.3 \%)$ \\
\hline マネジメントノリーダーシップ（Management/Leadership） & 31 & $(10.4 \%)$ & $31(12.8 \%)$ & 44 & $(13.0 \%)$ \\
\hline 社会・文化的側面（Socio-cultural） & 45 & $(15.1 \%)$ & $25(10.3 \%)$ & 47 & $(13.9 \%)$ \\
\hline 組織論／組織文化（Organizational theory/Culture） & 22 & $(7.4 \%)$ & $18(7.4 \%)$ & 28 & $(8.3 \%)$ \\
\hline 人材の多様性（Diversity） & 17 & $(5.7 \%)$ & $17(7.0 \%)$ & 20 & $(5.9 \%)$ \\
\hline 専門的職業準備（Professional preparation） & 10 & $(3.4 \%)$ & $15(6.2 \%)$ & 16 & $(4.7 \%)$ \\
\hline コミュニケーション（Communication） & 25 & $(8.4 \%)$ & $14(5.8 \%)$ & 20 & $(5.9 \%)$ \\
\hline ガバナンス（Governance） & 16 & $(5.4 \%)$ & $12(4.9 \%)$ & 10 & $(2.9 \%)$ \\
\hline 経済学（Economics） & 10 & $(3.4 \%)$ & $12(4.9 \%)$ & 14 & $(4.1 \%)$ \\
\hline 教授法（Teaching） & 13 & $(4.4 \%)$ & $11(4.5 \%)$ & 13 & $(3.8 \%)$ \\
\hline スポーツ・ツーリズム（Sport tourism） & 7 & $(2.3 \%)$ & $7(2.9 \%)$ & 10 & $(2.9 \%)$ \\
\hline 研究法（Research/Statistical methodology） & 6 & $(2.0 \%)$ & $7(2.9 \%)$ & 9 & $(2.7 \%)$ \\
\hline 法的問題（Legal aspects） & 7 & $(2.3 \%)$ & $6(2.5 \%)$ & 8 & $(2.4 \%)$ \\
\hline 金融論（Finance） & 5 & $(1.7 \%)$ & $2(0.8 \%)$ & 3 & $(0.9 \%)$ \\
\hline 倫理学 (Ethics) & 3 & $(1.0 \%)$ & $1(0.4 \%)$ & 8 & $(2.4 \%)$ \\
\hline 合計 & & 298 & 243 & & 339 \\
\hline
\end{tabular}




\section{研究発表}

以下では、本大会で発表数の多かったマーケティング、社会・文化的側面、マネジメント／リー ダーシップの分野に関して、研究動向を報告する。

\section{(1) マーケティング}

本大会では、マーケティング分野の研究が 89 題発表され、消費者行動やブランドといったトピ ックを扱う研究発表が多かった。中でも、興味深かったことは、ファンタジースポーツや e スポー ツを対象とした研究発表が増えていることである。過去 3 年間の学会抄録を遡ると、毎年 $1 \sim 2$ 題 の発表が行われているが、2016 年度は発表件数が増加していた。身体活動を伴わないファンタジ ースポーツや e スポーツを、いわゆる「スポーツ」に含めるべきか、またスポーツマネジメントと いう学問分野において研究対象とすべきかは、研究者の中でも議論は分かれている（松岡, 2010）。 しかし、2022 年の夏季アジア大会において e スポーツが正式競技として採用されたことは、今後 の e スポーツの展開を示唆する大きな動きであり、研究者および実務者としても動向を注視した いところである。今大会においては、例えば、Kim（2016）は、スポーツビデオゲーム（Madden NFL 25、NBA Live 14、FIFA 14）内に映る広告に対するユーザーのブランド認知、ブランドへの態 度、購買意図を調査し、繰り返しビデオゲームを行うことで、ブランド認知、ブランドへの態度が 高まっていることを明らかにした。さらに、ダイナミック広告を用いることで、ビデオゲームユ ーザーに対する広告効果を最大化できることも示した。また、ファンタジースポーツや e スポーツ 実施者、観戦者の増加に注目し、その動機を調査した研究も発表された（Drayer, Shapiro, \& Dwyer, 2016; Kota, Reid, James, \& Kim,2016; Pu, Son, \& Lin, 2016)。この他にも、マーケティングとは異なる が、組織論／組織文化の分野にて、e スポーツのマネジメントを論じた研究（Xue, Pu, Hawzen, \& Newman, 2016）もあり、研究トピックとして広がりを見せている。

\section{(2) 社会・文化的側面}

社会・文化的側面に関する研究は、近年増加傾向にあり、今大会では 47 題の研究発表があった。 主なトピックとしては、スポーツイベントの社会的効果、スポーツと健康、スポーツを通じた社会 的統合などが挙げられる。

スポーツイベントの効果に関しては、これまで多くの研究が経済的効果やツーリズムへの効果を 検証してきたが (e.g., Gratton, Shibli, \& Coleman, 2006; Preuss, 2005)、昨今、社会的効果の検証へと 関心がシフトしてきている。Inoue \& Heffernan（2016）は、多くの研究が西洋諸国で開催されたオ リンピックやスーパーボールなどの大規模スポーツイベントの社会的効果に注目していることを指 摘した上で、西洋諸国ではない国における小規模チャリティースポーツイベントの社会的効果を報 告した。この他にも、スポーツイベントの開催によるソーシャルキャピタルの創出(Djaballah,2016)、 障がい者を対象としたスポーツイベントを通じて、障がいに対する理解や障がい者スポーツの認知 度が深まるかどうかを検証した研究も発表された（Paradis, Misener, Legg, McGillivray, \& McPherson, 2016)。

スポーツと健康に関して、Cunningham（2016）は、高齢者や障がいを持つ人の割合が増加し、 その家族など介護する側への身体的、精神的な負担が増していることを指摘し、介護者の健康状態 とスポーツやレクリエーションの実施の関係を調査した。そして、介護者は、自身の健康状態（主 
観的健康状態）をネガティブに捉えている一方で、スポーツやレクリエーションの実施によって、 そのネガティブな影響が緩和されることを明らかにしている。高齢化社会の日本において、こうし た介護の問題は重要であり、スポーツを実施することの重要性、スポーツが果たせる役割を再認識 させられるものであろう。

\section{(3) マネジメント/リーダーシップ}

マネジメント/リーダーシップに関しては、44題の研究発表が行われ、従業員の職務満足度や リーダーシップといった組織行動論、スポーツ組織における女性の雇用やキャリアをテーマとする 研究が多くの割合を占めた。その中でも、近年の社会的トレンドをスポーツマネジメント研究に取 り入れた例を紹介する。Corral, Mala, McGarry（2016）は、近年、注目が集まる「グリット」に関 する研究を報告した。「グリット」とは、Duckworth, Peterson, Matthews,\& Kelly (2007) が提唱した「や り抜く力」「気概」といった人間の特性を意味し、近年、心理学において注目されている考え方である。 このグリットは子供の学業成績にも影響を与えることから、Corral, Mala, McGarry（2016）はスポ ーツプログラムを通じたグリットやリーダーシップ特性の発達について調査を実施し、グリット を高めるようなスポーツプログラムを子供に提供することの重要性を報告した。また、Anthony \& Funk（2016）は、スマートウォッチやフィットビットなどのフィットネス向けウェアラブル端末 の使用によって、ユーザーのスポーツ実施行動の変化を、行動変容ステージモデルを用いて検証し た。その結果、行動変容ステージモデルおける前熟考期に位置する人は、ウェアラブル端末を身に 着けることで、自身の身体活動レベルを認識し、スポーツ実施頻度が高くなることを明らかにした。

\section{基調講演}

基調講演には、オーランドに本拠地を置くNational Basketball Association（NBA）のチーム Orlando Magic の Marie Heikkinen-Webb 氏が登壇し、チームのマーケティング戦略について講演し た。オーランドは、Disney World や Universal Studio などのテーマパークがあり、全米で最も人気の 高い旅行先となっている。そのため、Orlando Magicでは「オーランド」という土地の特徴を活か し、ツーリズムと合わせたマーケティング戦略を行っている。チーム内には、ツーリズムマーケテ イング専門の部署が設置されており、アメリカ国内のみならず、イギリスやブラジル、カナダなど 世界各国からの旅行者に向けたマーケティングを展開している。Heikkinen-Webb 氏は旅行者がオ ーランド (旅行先) で期待していることとして、旅行先の地元文化を体験することやエンターテイ メントなどを挙げ、スポーツ観戦も 1 つのエンターテイメント体験となると述べていた。実際に、 Orlando Magic では、旅行代理店などと協力し、旅行者向けに観戦チケットの販売などを行ってい る。また、チームはグローバルブランディングも重要視している。これは、世界各地からの旅行者 が、自国に帰ったのちも Orlando Magic と接点を持ち続けられるような取り組みを実施し、チーム に対するロイヤリティを高めようという考えである。例えば、ソーシャルメディアを用いた情報の 発信や、ロンドンやブラジルなどでの試合開催は、その一例である。日本においても、昨今、スポ ーツツーリズムやスポーツを通じた地域活性が議論されているが、Heikkinen-Webb 氏の講演は、「ス ポーツチームが土地の利点をいかに活用できるか」という視点であり、世界的な観光地ならではの 特徵的なマーケティングとして興味深いものであった。 


\section{おわりに}

本稿では、北米のスポーツマネジメントの動向として、マーケティング、社会・文化的側面、マ ネジメントノリーダーシップの 3 つの分野を紹介した。筆者は今回、初めて NASSM に参加したが、 スポーツマネジメントにおける研究トピックの多様さを改めて実感し、スポーツマネジメントが学 際的な分野であることを再認識した。同時に、研究トピックの幅が広がり続けており、最新の研究 動向を知ることの重要性も認識させられた。

2017 度の NASSM は 2017 年 6 月 1 日より 6 月 3 日まで、コロラド州デンバーで開催される。コ ロラド州には NFL チームのコロラド・ブロンコスや MLB のコロラド・ロッキーズをはじめとす る7つのプロスポーツチームがあり、年間を通してスポーツを楽しめる場所である。また、デンバ 一はロッキー山脈の麓に位置しており、ハイキングなどのアウトドアスポーツでも人気のある場所 である。

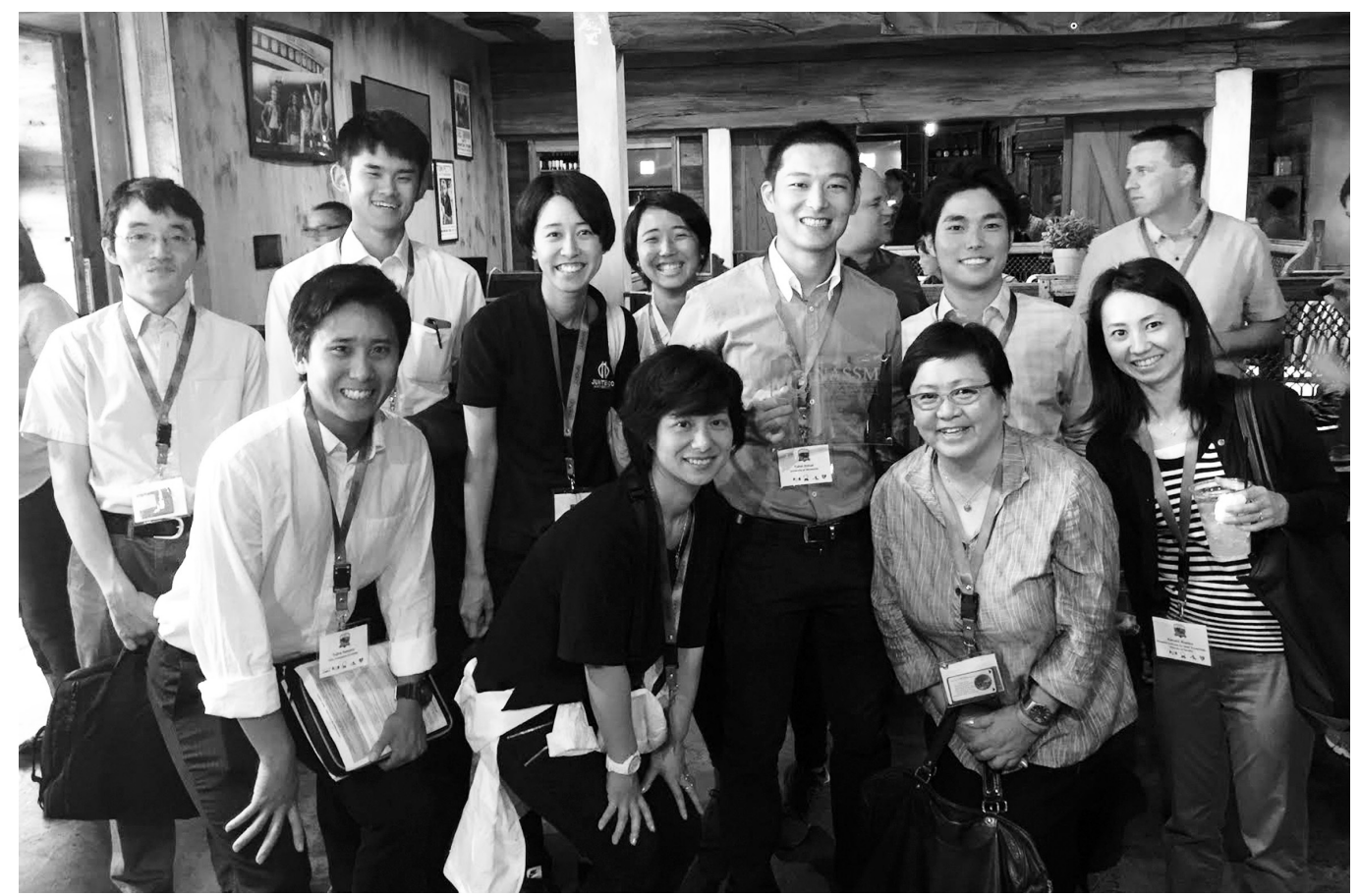

\section{【参考文献】}

Corral, M., Mala, J., \& McGarry, J. (2016) The Outcomes of an In-School SBYD Intervention Focused on Developing Grit and Leadership Characteristics. 20-minute oral presentation at the 31th North American Society for Sport Management Conference, Orlando, FL, USA.

Cunningham, G. (2016) Physical Activity Opportunities Mitigate the Negative Effects of Caregiving Obligations on Subjective Health. 20-minute oral presentation at the 31th North American Society for Sport Management Conference, Orlando, FL, USA.

Djaballah, M. (2016) Generating Social Capital through Major Sporting Events: a Social Network Analysis of UEFA Euro 2016's Local Hosting Dynamics. 20-minute oral presentation at the 31th North American Society for Sport 
Management Conference, Orlando, FL, USA.

Drayer, J., Shapiro, S., \& Dwyer, B. (2016) Exploring Motivations of Daily Fantasy Sports Participants. 20-minute oral presentation at the 31th North American Society for Sport Management Conference, Orlando, FL, USA.

Duckworth, A. L., Peterson, C., Matthews, M. D., \& Kelly, D. R. (2007) Grit: Perseverance and passion for long-term goals. Journal of Personality and Social Psychology, 92(6), 1087-1101.

Gratton, C., Shibli, S., \& Coleman, R. (2006). The economic impact of major sports events: a review of ten events in the UK. The Sociological Review, 54, 41-58.

Inoue, Y. \& Heffernan, C. (2016) A Qualitative Assessment of Social Impact of a Charity Sport Event in Cambodia. 20-minute oral presentation at the 31th North American Society for Sport Management Conference, Orlando, FL, USA.

Kim, Y. (2016) Effectiveness of In-Game Advertisement: Repetition Effect of Sport Video Gaming. 20-minute oral presentation at the 31th North American Society for Sport Management Conference, Orlando, FL, USA.

Kota, R., Reid, C., James, J., \& Kim, A. Daily Fantasy Sports: Motives for Consumption. 20-minute oral presentation at the 31 th North American Society for Sport Management Conference, Orlando, FL, USA.

松岡宏高.“スポーツマネジメントの概念の再検討.”スポーツマネジメント研究 2.1（2010）:33-45.

Paradis, K., Misener, L., Legg, D., McGillivray, D., \& McPherson, G. (2016) (Para)Panamania: The Influnece of the Toronto 2015 ParaPan Am Games on Spectator and Volunteer Attitudes Towards Disability. 20-minute oral presentation at the 31th North American Society for Sport Management Conference, Orlando, FL, USA.

Pizzo, A. \& Funk, D. (2016) Wearable Fitness Technology and Exercise Change Behavior. 20-minute oral presentation at the 31th North American Society for Sport Management Conference, Orlando, FL, USA.

Preuss, H. (2005). The economic impact of visitors at major multi-sport events. European Sport Management Quarterly, 5, 281-301.

Pu, H., Son, H., \& Lin, Z. (2016) Exploring Spectator Motivations for Attending E-Sports Events. Poster presentation at the 31 th North American Society for Sport Management Conference, Orlando, FL, USA.

Xue, H., Pu, H., Hawzen,M., \& Newman, J. (2016) E-Sports Management? Institutional Logics, Professional Sports, Emerging E-Sports Field. 20-minute oral presentation at the 31th North American Society for Sport Management Conference, Orlando, FL, USA. 